\title{
Who's in Control? Proficiency and L1 Influence on L2 Processing
}

\author{
Kerrie E. Elston-Güttler, Silke Paulmann, and Sonja A. Kotz
}

\begin{abstract}
We report three reaction time (RT)/event-related brain potential (ERP) semantic priming lexical decision experiments that explore the following in relation to $\mathrm{L} 1$ activation during $\mathrm{L} 2$ processing: (1) the role of L2 proficiency, (2) the role of sentence context, and (3) the locus of L1 activations (orthographic vs. semantic). All experiments used German (L1) homonyms translated into English (L2) to form prime-target pairs (pine-jaw for Kiefer) to test whether the L1 caused interference in an all-L2 experiment. Both RTs and ERPs were measured on targets. Experiment 1 revealed reversed priming in the N200 component and RTs for low-proficiency learners, but only RT interference for high-proficiency participants. Experiment 2 showed that once the words were processed in sentence context, the low-proficiency participants still showed
\end{abstract}

\section{INTRODUCTION}

Several behavioral and neurocognitive studies suggest that a person who can speak two languages has available many different types of connections between words in their first language (L1) and second language (L2) (e.g., Kotz \& Elston-Güttler, 2004; Kroll \& Stewart, 1994; Williams, 1994; Kirsner, Smith, Lockhart, King, \& Jain, 1984). Even if we assume two separate lexicons, words in each language form a network connected on many levels: at the word form level (Kroll \& Stewart, 1994), at the level of morphosyntactic coding, the lemma (ElstonGüttler, 2000; Kroll \& De Groot, 1997), and finally, at the semantic or conceptual level where two vocabulary systems are linked to general cognition (Levelt, Roelofs, \& Meyer, 1999; Kroll \& Stewart, 1994). With all of these interfaces, how can a bilingual actually function in the L1 or the L2 without constant influence of one language on the other? This issue, which we refer to as cognitive control in language processing (see also Dijkstra \& Van Heuven, 2002), is the topic of the present study.

\section{Bilingual Cognitive Control}

Up until now, the issue of language control in bilingual language recognition has been investigated using the

Max Planck Institute for Human Cognitive \& Brain Sciences reversed N200 and RT priming, whereas the high-proficiency group showed no effects. Experiment 3 tested native English speakers with the words in sentence context and showed a null result comparable to the high-proficiency group. Based on these results, we argue that cognitive control relating to translational activation is modulated by (1) L2 proficiency, as the early interference in the N200 was observed only for low-proficiency learners, and (2) sentence context, as it helps high-proficiency learners control L1 activation. As reversed priming was observed in the N200 and not the N400 component, we argue that (3) the locus of the L1 activations was orthographic. Implications in terms of bilingual word recognition and the functional role of the N200 ERP component are discussed. case of interlingual homographs, or false friends, where a single-word form such as chef presents a bilingual with two completely different L1 and L2 meanings (chef refers to "cook" in English and "boss" in German). Some earlier studies argue for language selectivity (e.g., Gerard \& Scarborough, 1989; Scarborough, Gerard, \& Cortese, 1984; Soares \& Grosjean, 1984), a position that assumes that only one language is activated at a time. However, there is a range of phenomena observed in more recent studies that support a nonselective bilingual wordrecognition system, that is, a system that allows for parallel activation of both languages where influence of one language while processing in the other is likely (Chen \& Ho, 1986, in Stroop interference; Smith \& Kirsner, 1982, in bilingual picture-word distractor tasks; De Bruijn, Dijkstra, Chwilla, \& Schreifers, 2001; Van Heste, 1999; De Moor, 1998; Grainger \& Dijkstra, 1992; Beauvillain \& Grainger, 1987, in primed lexical decision tasks [LDTs]; Dijkstra et al., 1999; De Groot, Delmaar, \& Lupker, 2000, in non-primed LDTs). Task itself is also crucial (cf. Dijkstra, De Bruijn, Schreifers, \& Brinke, 2000; Dijkstra, Timmermans, \& Schreifers, 2000; Dijkstra, Van Jaarsveld, \& Brinke, 1998). In nonprimed LDTs, all-L2 stimuli lists result in selective access (cf. Dijkstra, De Bruijn, et al., 2000). These task effects have been accounted for in Green's (1998) inhibitory control (IC) model with so-called task schemas assuming that language switches from one trial to the next cause 
activation of both languages. However, primed LDTs with all-L2 stimuli lists show nonselective access of interlingual homographs (Elston-Güttler, 2000; Van Heste, 1999; De Moor, 1998; for a similar effect of the L2 on the L1, see Van Hell \& Dijkstra, 2002), suggesting a role of semantics in relation to task schemas.

For example, Elston-Güttler (2000) found with German intermediate learners of English that in single-word lists, interlingual homographs such as gift prime their L1 meanings, for example, poison with a stimulus onset asynchrony (SOA) of $250 \mathrm{msec}$ between prime and target. However, when primes were presented at the end of full sentences such as "The woman gave her friend an expensive gift," the priming effects disappeared. Such semantic context effects (obtained in Elston-Güttler, 2000, or in Altarriba, Kroll, Sholl, \& Rayner, 1996), in addition to the task effects, can be accounted for in the more recent Bilingual Interactive Activation $(\mathrm{BIA}+)$ model by Dijkstra \& Van Heuven (2002). The BIA + model of bilingual word recognition assumes a distinction between nonlinguistic task effects and linguistic (semantic and syntactic) context effects.

To help in our understanding of the physiological and behavioral mechanisms underlying the bilingual wordrecognition system, we felt that a test of another L1-L2 relationship other than interlingual homographs would be beneficial. Therefore, the present study examines cases of L1-L2 relationships that occur at a so-called translational level, that is, potentially both at the word form and/or semantic level. An L1 homonym such as Kiefer translates into two distinct lexical forms that are semantically unrelated in the L2, jaw and pine. By virtue of their shared translation, the two words are competitors, as only one translation can be appropriate in a given context (see Figure 1 for a depiction of this). The potential inhibitory relationship between L1 homonym translations can tell us how L1 meaning activation affects L2 processing. Using the joint measure of RTs and ERPs, we look especially at the N200 component, which may reflect word-level processing, and at the N400 component, which is an indicator of semantic integration, to determine whether the L1 influence we are testing is operating at the word form or at the semantic level.

\section{Inhibition of Competing Homonym Meanings}

Tokowicz (2001) found that words with a higher number of potential translation candidates have longer translation latencies and lower accuracy rates, suggesting that translation options compete with one another (see Figure 1 similar to Kroll \& Tokowicz, 2002). Direct evidence of homonym meaning competition was also obtained in a single-word LDT by Elston (1996). Inhibition, or what we will refer to as reversed priming, was obtained for one homonym translation pine after presentation of the other translation jaw, that is, longer RTs

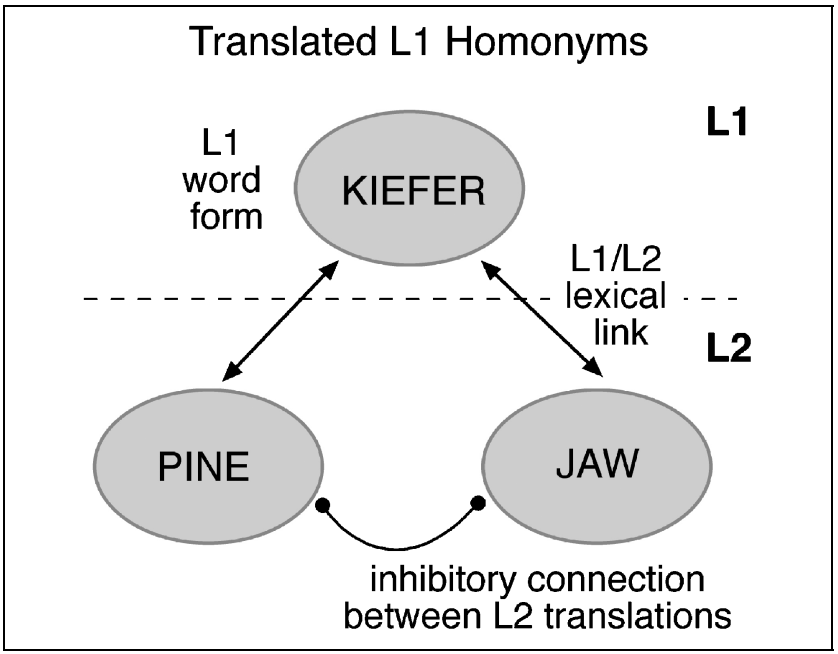

Figure 1. Representation of translated L1 homonyms in the L1/L2 mental lexicon. We assume that the word form entry for Kiefer is connected to both of its L2 translation word form entries pine and jaw and that there is an inhibitory connection between the translations. Thus, when pine is presented, reversed priming of jaw could be observed in the ERPs or RTs (see text for more detailed predictions).

for related pairs than for unrelated pairs was obtained with an SOA of $250 \mathrm{msec}$ when intermediate German learners of English were tested (Elston, 1996). Similar reversed priming effects were obtained with intermediate German learners of English in a cross-modal semantic LDT with sentence-imbedded translated homonyms (Wagner, 1996). Interestingly, with intermediate learners, Elston-Güttler (2000) obtained facilitation of related translated homograph pairs (with an SOA of $250 \mathrm{msec}$ ) in both single word and sentence contexts, which was argued to reflect the fact that translational relationships at the semantic level between the L1 and the L2 are more resistant to semantic sentence contexts than are interlingual homographs, whose L1-L2 relationships are form level. Although it is not yet clear why the direction (i.e., facilitation or reversed priming) of the effects obtained in the above studies differed, ${ }^{1}$ both sentence studies (Elston-Güttler, 2000; Wagner 1996) suggest that translational level effects can be obtained in biased semantic contexts in an all-L2 task context, whereas this is not the case for interlingual homographs (see Elston-Güttler, 2000; Elston-Güttler, Gunter, \& Kotz, in press). What we aim to address in this study by looking at both RTs and ERPs is (1) whether effects are really inhibitory in single-word lists and in sentence contexts and (2) whether translated homonym processing differs as a function of L2 proficiency.

A study by Chwilla and Kolk (2003) measured RTs and ERPs to triplet-final ambiguous words in a semantic judgement task and reported underadditive priming in the RTs and ERPs. Based on Balota and Paul (1996) where a similar RT effect was obtained, the authors 
argue that this occurs because the buildup of activation from the first prime at the semantic level for one meaning inhibits the buildup of activation from the second prime to the other meaning. As the underadditive effect was obtained in the N400 component, then inhibition of homonym meanings may take place at the level of postlexical meaning integration. It is not clear whether translations of L1 homonym meanings are processed similarly, but the assumption from Chwilla and Kolk that homonym meanings are competitors with inhibitory connections seems to be solid.

\section{Cognitive Control and ERPs}

N400 semantic priming in LDTs has already been studied in L2 processing (Kotz \& Elston-Güttler, 2004; Kotz, 2001) and the issue of cognitive control in particular (De Bruijn, Dijkstra, et al., 2001). De Bruijn et al. (2001) reported that Dutch-English bilinguals show an N400 for targets that are semantically related to the English reading of a Dutch-English homograph prime such as angel ("sting" in Dutch). This effect was obtained regardless of whether the pair was preceded by an English-only or Dutch-only word. That is, there was priming of heaven in both the triplets house-angelbeaven and zaak-angel-heaven (zaak means "case" or "shop"). This study suggests L1 influence on L2 processing in both L1 and L2 trial contexts and that the activations were semantic as the N400 was involved.

However, it is not clear whether the influence caused by translated homonyms really reflects semantic processing, so L1 influence during L2 processing may be observed in another ERP component, the N200. The ERP literature on the functional correlates of the N200 identify three main areas: (1) response inhibition (discussed in, e.g., Rodriguez-Fornells, Schmitt, Kutas, \& Münte, 2002), (2) the so-called phonological mismatch negativity (e.g., Van den Brink, Brown, \& Hagoort, 2001; Connolly \& Phillips, 1994), and (3) aspects of orthographic word form level processing (e.g., Bentin, Mouchetant-Rostaing, Girad, Echallier, \& Pernier, 1999; Niznikiewicz \& Squires, 1996; Compton, Grossbacher, Posner, \& Tucker, 1991; Kramer \& Donchin, 1987). The functional correlate relating to response inhibition is the so-called N200 no-go component. The N200 is often observed in the go/no-go paradigm, where a participant is asked to respond to a certain type of stimuli (go) and to withhold responses to another type (no-go). Several studies obtained an early frontal negativity beginning at about 200 msec to no-go responses as compared to go responses (Thorpe, Fize, \& Marlot, 1996; Eimer, 1993; Jodo \& Kayama, 1992; Kok, 1986). Even though our present task is not a go/no-go task, the N200 may reflect the relative difficulty of the lexical decision of two competing targets. In LDTs, the participant is not asked to make or withhold a response, but rather to make a word/not-word decision. However, if the two homonym meanings are competitors, the lexical decision for related words should be more difficult. Unrelated targets, on the other hand, are not inhibited due to L1 activation and are analogous to a go response where a smaller N200 is observed. Any difference in the N200 amplitudes between related and unrelated conditions, therefore, can tell us something about the relative difficulty of lexical decision.

The second relevant functional correlate of the N200 relates to word form or orthographic processing. Although the N200 appears as a function of phonological mismatch in auditorily presented tasks (e.g., van den Brink, Brown, \& Hagoort, 2001; Connelly \& Phillips, 1994; Connolly, Phillips, Stewart, \& Brake, 1992; Connolly, Stewart, \& Phillips, 1990), the N200 has also been observed in visual processing when words are phonologically related (Niznikiewicz \& Squires, 1996; Kramer \& Donchin, 1987). In addition, the N200 is proposed to reflect orthographic processing in visually presented tasks. Compton et al. (1991) observed an early negativity that was larger to consonant strings than to words across the tasks of passive reading, feature detection, and letter decision tasks, but reversed in the LDT. Moreover, Bentin et al. (1999) reported a so-called NI70 that was larger for orthographic words (words, pronounceable words, and letter strings) than to nonorthographic stimuli (symbols and forms) in a size judgement task. The direction of the N200 effects (words sometimes more negative, sometimes more positive, than letter strings) seems to depend on the type of task. However, the data from the above studies suggest that the ERPs recorded at posterior sites within the 150-250 time window are modulated by orthographic - or word form-processing.

Given that it is not clear whether translated homonym influence on the 22 results from word form connections reflected by the $\mathrm{N} 200$ or semantic processes reflected by the N400, our study aims to pinpoint the locus of these phenomena. Translational or lexical links across languages are thought to reflect links where learners have an associative connection between an L1 word to an L2 word developed in the language learning process (e.g., in the revised hierarchical model or RHM of Kroll \& Stewart, 1994). In the RHM, the assumption is that word form is represented separately in L1 and L2 (see Gerard \& Scarborough, 1989), whereas word meaning is represented in a common conceptual system for both languages. However, the so-called lexical link connecting L1 and L2 words could refer to both the word form level (orthographic and phonological representation of the word) or to the lemma level where word characteristics such as basic semantics and morphosyntactic information is believed to be stored (Levelt, 1989). Therefore, it is not clear whether multiple meanings inhibit each other on purely the word form or on a semantic level. In Elston-Güttler (2002), it was argued that interlingual homographs operate at the semantic level, explaining 
why L1 influence on the L2 remains even in sentence contexts. However, given the fact that translational word form linkages between languages are in place quite early in learning (Dufour \& Kroll, 1995) and operate in a more automatic way than do word-toconcept connections (Kotz \& Elston-Güttler, 2004), we cannot rule out the possibility that L1 homonym influence on the L2-even in semantic sentence contextmay still operate at the level of word form. With the ERP measure, we can test this, as purely word form interference is likely to be reflected in the N200 component, whereas semantic interference should be reflected in the N400 component.

Also of relevance to the present study and to the RHM discussed above is the issue of L2 proficiency or the general language ability and experience of L2 learners. A developmental interpretation of the RHM (cf. Chueng \& Chen, 1998; Dufour \& Kroll, 1995) assumes that low-proficiency learners process the L2 through L1-L2 lexical links, not via the common conceptual system until fuller proficiency in the L2 is achieved. In this framework, the L1-L2 lexical links that enable the L2 interference we are testing to come into play are not relied on to the same degree by highly proficient learners than by less fluent L2 learners. With increased proficiency, the conceptual links between L2 words and their translations become stronger, making reliance on the lexical links less profound. A range of behavioral studies (e.g., Gascoigne, 2001; Chueng \& Chen, 1998; Bijeljac-Babic, Biardeau, \& Grainger, 1997; Frenck-
Mestre \& Prince, 1997; Dufour \& Kroll, 1995; Woutersen, De Bot, \& Weltens, 1995; Kawakami, 1994) and ERP studies (Kotz \& Elston-Güttler, 2004; Kotz, 2001; WeberFox \& Neville, 1996) also suggest that proficiency level is a significant factor in L2 lexical processing. Therefore, with translated L1 homonyms, we aim to test not only the locus of interference obtained in single-word tasks and during sentence processing, but whether such interference is modulated by L2 proficiency.

\section{EXPERIMENT 1}

The purpose of Experiment 1 was to examine whether cross-language interference effects between the translations of L1 homonyms are observed in RTs and ERPs in an all-L2 single-word list presentation, and whether such effects are determined by level of L2 proficiency. To this end, we conducted an LDT completely in English presented to German L2 learners of English with either high or low English proficiency as measured by an extensive language background questionnaire and post-testing (see Table 1). RTs and ERPs were measured on targets (e.g., jaw) that were preceded by translated homonym (i.e., pine) or unrelated primes (i.e., oak) (see Table 2 for stimuli examples). The SOA between the end of prime presentation and target onset was $200 \mathrm{msec}$. Two homonym types were included. The first type, called HOM, were German words with two unambiguous English translations that served as prime and target, and

Table 1. L2 Learner Participant Proficiency Data (Experiments 1 and 2)

\begin{tabular}{|c|c|c|c|c|c|c|}
\hline & \multicolumn{3}{|c|}{ Highs } & \multicolumn{3}{|c|}{ Lows } \\
\hline & $\begin{array}{c}\text { Experiment } 1 \\
(n=20)\end{array}$ & $\begin{array}{c}\text { Experiment } 2 \\
(n=17)\end{array}$ & $\begin{array}{c}\text { Total } \\
(n=37)\end{array}$ & $\begin{array}{l}\text { Experiment } 1 \\
\quad(n=20)\end{array}$ & $\begin{array}{c}\text { Experiment } 2 \\
(n=17)\end{array}$ & $\begin{array}{c}\text { Total } \\
(n=37)\end{array}$ \\
\hline Age (years) & 23.4 & 23.2 & 23.4 & 23.1 & 22.3 & 22.7 \\
\hline Sex (number, \% females) & $17(85)$ & $13(76)$ & $30(81)$ & $19(95)$ & $11(65)$ & $30(81)$ \\
\hline Age of acquisition (years) & 12.1 & 11.8 & 12.0 & 11.7 & 12.0 & 11.8 \\
\hline Months abroad, English exposure ${ }^{a}$ & 13.7 & 14.7 & 14.1 & 6.9 & 5.8 & 6.5 \\
\hline Listening $^{\mathrm{b}}$ & 8.9 & 8.6 & 8.8 & 8.5 & 8.1 & 8.3 \\
\hline Reading $^{\mathrm{b}}$ & 8.7 & 8.3 & 8.4 & 8.2 & 8.3 & 8.2 \\
\hline Speaking ${ }^{\mathrm{a}, \mathrm{b}}$ & 8.7 & 8.5 & 8.6 & 7.8 & 7.3 & 7.5 \\
\hline Writing ${ }^{a, b}$ & 8.4 & 7.8 & 8.1 & 7.6 & 6.9 & 7.3 \\
\hline Independence $e^{\mathrm{a}, \mathrm{b}}$ & 8.9 & 8.7 & 8.8 & 7.5 & 6.9 & 6.2 \\
\hline Vocabulary test (\%) ${ }^{\mathrm{a}}$ & 91.7 & 93.2 & 92.2 & 88.8 & 85.2 & 87.2 \\
\hline Memory recall task (\%) & 70.2 & 79.8 & 74.3 & 69.3 & 82.9 & 75.3 \\
\hline
\end{tabular}

Mean average scores and L2 proficiency ratings for high- versus low-proficiency participants by experiment (1 vs. 2$)$ and in total.

${ }^{\mathrm{a} S}$ Significant difference between highs total and lows total at $p=.01$ (one-way ANOVA).

${ }^{\mathrm{b}}$ Self-rating of ability in English on a scale of 1 to 10. 
Table 2. Examples of Stimuli Materials by Word Type and Condition (Experiments 1-3)

\begin{tabular}{|c|c|c|}
\hline Condition & Sentence/Prime & Target \\
\hline \multicolumn{3}{|l|}{ HOM } \\
\hline \multicolumn{3}{|c|}{ Dominant Prime, Subordinate Target } \\
\hline 1 REL & $\begin{array}{l}\text { The sticky candy stuck together } \\
\text { his jaw }\end{array}$ & PINE \\
\hline 2 UREL & $\begin{array}{l}\text { The sticky candy stuck together } \\
\text { his teeth }\end{array}$ & PINE \\
\hline \multicolumn{3}{|c|}{ Subordinate Prime, Dominant Target } \\
\hline 3 REL & $\begin{array}{l}\text { The beautiful table was made of } \\
\text { solid pine }\end{array}$ & JAW \\
\hline 4 UREL & $\begin{array}{l}\text { The beautiful table was made of } \\
\text { solid oak }\end{array}$ & JAW \\
\hline \multicolumn{3}{|l|}{ CSE } \\
\hline \multicolumn{3}{|c|}{ Dominant Prime, Subordinate Target } \\
\hline 1 REL & Jane was forced to pay the duty & INCH \\
\hline 2 UREL & Jane was forced to pay the bill & INCH \\
\hline \multicolumn{3}{|c|}{ Subordinate Prime, Dominant Target } \\
\hline 3 REL & $\begin{array}{l}\text { The carpenter increased the width } \\
\text { by an inch }\end{array}$ & DUTY \\
\hline 4 UREL & $\begin{array}{l}\text { The carpenter increased the width } \\
\text { by a meter }\end{array}$ & DUTY \\
\hline
\end{tabular}

The HOM words were two nonambiguous English translations (pine and jaw) of German homonyms (Kiefer). The CSE words were two translations (inch and duty) of a German homonym (Zoll), but one of the translations $(d u t y)$ is also ambiguous in English. Experiment 1 used the single-word primes in boldface and targets only, whereas Experiments 2 and 3 included the preceding sentences.

these English translations had a mean frequency of 33.7 per million (see Table 3 for frequency breakdowns). The second type, called contrast of semantic extension (or CSE, cf. Elston-Güttler, 2000), had two English translations, but one of the English words was ambiguous, meaning that the English translations were also more frequent, with a mean of 75.4 per million (see Table 2 for examples and Methods for more on word types).

The experiment had a $2 \times 2 \times 2 \times 2$ design with a two-level, between-subjects factor of proficiency Group (high vs. low) and two-level, within-subjects factors of Relatedness (Rel: target related vs. unrelated to the prime), Dominance (Dom: target reflecting the dominant vs. subordinate meaning of the German homonym), and Ambiguity Type (AmbType: German homonym reflecting either a single or double ambiguity, i.e., HOM vs. CSE items).

We predict that for both proficiency groups, we will observe reversed RT priming of the type observed in Elston (1996) and Wagner (1996), and in the ERPs, we expect to observe reversed priming in the N200 component or in the $\mathrm{N} 400$ component, or in both. As the N200 reflects both response inhibition and orthographic processing, N200 priming in the absence of N400 priming would indicate orthographic L1 influence as opposed to semantic. If reversed priming is obtained in the N400 in the absence of an effect in the N200, this suggests semantic influence from the L1. Last, effects in both the N200 and N400 might indicate early orthographic influence followed by semantic activations from the L1. Although we anticipate effects in both high and low groups, a much stronger word form interference effect is expected for the low-proficiency group, and with more profound L1 influence, the dominance of the meanings from German may play more of a role. This means that we may observe more substantial reversed RT priming and modulation of the N200 or N400 component on the part of less proficient learners than for more proficient learners. This prediction is based on the developmental interpretation of the RHM (Chueng \& Chen, 1998; Dufour \& Kroll, 1995) previously discussed. A range of other behavioral studies (e.g., Gascoigne, 2001; Chueng \& Chen, 1998; Bijeljac-Babic et al., 1997; Frenck-Mestre \& Prince, 1997; Dufour \& Kroll, 1995; Woutersen et al., 1995; Kawakami, 1994) and ERP studies (Kotz \& Elston-Güttler, 2004; Kotz, 1996, 2001; Weber-Fox \& Neville, 1996) also suggest

Table 3. Sentence Length and Prime and Target Letter Length and Frequency of Critical Items (Experiments 1-3)

\begin{tabular}{lccccc}
\hline Condition & $\begin{array}{c}\text { Sentence Count } \\
\text { (Experiments 2 and 3) }\end{array}$ & Prime Frequency $^{a}$ & Prime Letter Length & Target Frequency $^{b}$ & Target Letter Length $^{\text {Trim }}$ \\
\hline CSE & $6.6(1.1)$ & $73.8(95.0)$ & $5.4(1.8)$ & $75.4(97.6)$ & $5.0(1.5)$ \\
HOM & $7.0(1.2)$ & $35.3(37.3)$ & $6.2(2.2)$ & $33.7(35.4)$ & $6.2(2.4)$ \\
Mean & $6.8(1.1)$ & $54.2(74.1)$ & $5.8(2.0)$ & $5.6(2.1)$ & $54.1(75.7)$ \\
\hline
\end{tabular}

$S D$ s are listed in parentheses after each mean. Mean sentence length is in words, whereas prime and target frequency is reported as mean occurrences per million using the English lemma frequency dictionary in the CELEX lexical database (Baayen, Piepenbrock, \& Van Rijn, 1993).

${ }^{a}$ Mean frequency per million of test and corresponding control prime words.

${ }^{b}$ Mean frequency per million of test target words (reflects the means of the test translations only) 
that proficiency level is a significant factor in L2 lexical processing and motivate our predictions.

\section{EXPERIMENT 1: BEHAVIORAL DATA}

\section{Analysis of Accuracy}

See Table 4 for error data, and see Table 5 for a summary of significant effects. Over both proficiency groups, there was a significant Rel effect, $F(1,38)=$ $8.52, p=.006$, revealing reversed priming with related targets resulting in a higher error rate (11.2\%) than unrelated targets (9.3\%). There was also a significant AmbType effect, $F(1,38)=8.98, p=.005$, indicating a higher error rate (11.4\%) for HOM targets than for CSE targets (9.2\%) as well as a significant Dom effect, $F(1,38)=49.71, p<.001$, with the subordinate targets resulting in a higher error rate (13.2\%) than dominant targets (7.4\%). These factors, however, did not interact with Group $(F=0.73$ for Dom, $F=0.17$ for Rel, and
$F=2.01$ for AmbType). Overall, the error data indicate difficulty with the related targets of both word types and, in particular, with the HOM word type and subordinate targets.

\section{Analysis of RTs}

See Table 4 for RTs and SDs, and see Table 5 for $F$ values for significant effects. In the analysis of correct RTs over both proficiency groups, there was a main effect of Rel that only approached significance, $F(1,38)=3.62, p=.065$. There was also a significant AmbType effect, $F(1,38)=18.93, p<.0001$, with CSEs (784 msec) faster than HOMs (806 $\mathrm{msec})$, and a significant Dom effect, $F(1,38)=48.53, p<.0001$, with subordinate meanings resulting in slower (821 msec) RTs than dominant meanings (769 $\mathrm{msec})$. There was also a tendency toward an interaction between Dom and Rel, which, when broken down, showed reversed priming of

Table 4. Mean RT, $S D$, and Percent Errors by Participant Group (Experiments 1-3)

\begin{tabular}{|c|c|c|c|c|c|c|c|}
\hline & \multicolumn{3}{|c|}{ Related } & \multicolumn{3}{|c|}{ Unrelated } & \multirow{2}{*}{$\frac{\text { Priming }}{+/-}$} \\
\hline & $R T$ & $S D$ & Error (\%) & $R T$ & $S D$ & Error (\%) & \\
\hline \multicolumn{8}{|c|}{ Experiment 1 (single word) } \\
\hline High Proficiency & 802 & 142 & 10.1 & 792 & 136 & 8.6 & -10 \\
\hline Dominant targets & 791 & 159 & 7.5 & 755 & 124 & 6.3 & $-36^{*}$ \\
\hline Subordinate targets & 813 & 129 & 13.0 & 829 & 154 & 10.9 & +16 \\
\hline Low Proficiency & 801 & 182 & 12.2 & 787 & 190 & 10.0 & -14 \\
\hline Dominant targets & 774 & 174 & 8.1 & 756 & 176 & 7.7 & -18 \\
\hline Subordinate targets & 828 & 202 & 16.3 & 817 & 208 & 12.4 & $-\mathbf{1 1}$ \\
\hline \multicolumn{8}{|c|}{ Experiment 2 (sentences) } \\
\hline High Proficiency & 816 & 148 & 10.6 & 809 & 155 & 10.2 & -7 \\
\hline Dominant targets & 800 & 146 & 6.7 & 780 & 111 & 6.9 & -20 \\
\hline Subordinate targets & 833 & 154 & 14.4 & 838 & 186 & 13.5 & +5 \\
\hline Low Proficiency & 823 & 145 & 8.8 & 777 & 140 & 8.0 & $-46 *$ \\
\hline Dominant targets & 801 & 121 & 7.1 & 759 & 124 & 6.5 & $-42 *$ \\
\hline Subordinate targets & 845 & 165 & 10.6 & 795 & 153 & 11.6 & $-50 *$ \\
\hline \multicolumn{8}{|c|}{ Experiment 3 (sentences) } \\
\hline Native Speakers & 745 & 199 & 4.5 & 753 & 169 & 4.6 & 8 \\
\hline Dominant targets & 735 & 204 & 3.2 & 752 & 171 & 3.6 & 17 \\
\hline Subordinate targets & 755 & 197 & 5.9 & 754 & 170 & 6.6 & $-\mathbf{1}$ \\
\hline
\end{tabular}

Mean response times in milliseconds with standard deviation and error rates comparing high- and low-proficiency groups tested in Experiments 1 and 2 and the native English speaker control group tested in Experiment 3.

${ }^{*} p<.05$, significant in the one-way ANOVA performed for that condition. 
Table 5. Experiment 1: Summary of Significant Main Effects, Interactions, and Step-down Analyses for Accuracy, RT, and ERP Data

\begin{tabular}{|c|c|c|c|c|c|c|c|c|}
\hline \multicolumn{3}{|c|}{ Accuracy } & \multicolumn{3}{|c|}{$R T$} & \multicolumn{3}{|c|}{ ERP Time Window, 100-200 msec } \\
\hline Factor $(s)$ & $d f$ & $F$ Value & $\operatorname{Factor}(s)$ & $d f$ & F Value & $\operatorname{Factor}(s)$ & $d f$ & $F$ Value \\
\hline Rel & 1,38 & $8.52 * *$ & Rel & 1,38 & $3.62^{+}$ & Rel $\times$AmbType & 1,38 & $17.28 * *$ \\
\hline AmbType & 1,38 & $8.98 * *$ & AmbType & 1,38 & $18.93 * * * *$ & HOM Rel & 1,38 & $13.37 * *$ (priming) \\
\hline \multirow[t]{7}{*}{ Dom } & 1,38 & $49.71 * * * *$ & Dom & 1,38 & $48.53 * * * *$ & CSE Rel & 1,38 & $6.59 *$ (reversed priming) \\
\hline & & & Dom $\times$ Rel & 1,38 & $3.25^{+}$ & Group $\times$AmbType $\times$Dom & 1,38 & $4.17^{*}$ \\
\hline & & & Dominant Rel & 1,38 & $6.50 *$ & Group $\times$ AmbType $\times$ Rel & 1,38 & $3.90^{+}$ \\
\hline & & & Subordinate Rel & 1,38 & $.08 n s$ & Low Group: & & \\
\hline & & & & & & Rel $\times$ AmbType & 1,19 & $20.96 * * *$ \\
\hline & & & & & & HOM Rel & 1,19 & $14.48 * * *$ (priming) \\
\hline & & & & & & CSE Rel & 1,19 & $10.70 * *$ (reversed priming) \\
\hline
\end{tabular}

F values and significance levels are listed for significant main effects and interactions in the omnibus analysis on Error, RT, and ERP data, along with significant statistics in relevant step-down analyses. All effects not listed in the table are not significant $(p$ values $>.1)$.

$* p<.05$.

$* * p<.01$.

$* * * p<.001$.

$* * * * p<.0001$

${ }^{+} p<.01$.

27 msec with a significant main effect of Rel over groups for dominant targets, $F(1,38)=6.50, p=.015$, but not for subordinate targets, $F(1,38)=0.08$.

\section{EXPERIMENT 1: ELECTROPHYSIOLOGICAL DATA}

\section{Visual Inspection of ERPs}

See Figure 2 for Experiment 1 ERP data. Based on visual inspection, an early negativity (the N200) can be seen peaking at about $150 \mathrm{msec}$ poststimulus, followed by another negativity (the N400) that peaks at around $450 \mathrm{msec}$, ending with a positive-going wave at parietal electrode sites peaking at $600 \mathrm{msec}$ (P600). Modulations dependent on Rel are observable only in the first component. As the main effect of, and interactions with, Rel were not significant in the time windows of 300-500 and 500-700 msec (all $p$ values $>$. 1), only data pertaining to the N200 time window are reported below.

\section{0-200 msec}

See Table 5 for a summary of significant effects. Within this time window, there were no significant main effects (all $p$ values $>.1$ ). There was a significant interaction between Rel and AmbType, $F(1,38)=17.28, p=.002$, with significant Rel effects for $\operatorname{HOM}, F(1,38)=13,37$, $p=.001$ (standard priming), and for CSE, $F(1,38)=$ 6.59, $p=.014$ (reversed priming). There was also a three-way interaction between Group, AmbType, and
Dom, $F(1,38)=4.17, p=.048$, along with a three-way interaction between Group, AmbType, and Rel that approached significance, $F(1,38)=3.90, p=.056$.

To explore the three-way interactions, step-down analyses by proficiency group were performed. For the low group, the Dom by AmbType interaction, $F(1,19)=$ 1.25, was not significant, but the interaction between Rel and AmbType, $F(1,19)=20.96, p=.0002$, was significant. An analysis by AmbType yielded a significant Rel effect for $\mathrm{HOM}, F(1,19)=14.48, p<.001$ (see Figure $2 \mathrm{~A}$ ), indicating a standard priming effect with the N200 smaller for related targets. In contrast, the CSE word type showed a significant Rel effect, $F(1,19)=10.70, p=$ .004 (see Figure 2B), indicating reversed priming. For the high-proficiency group, the Rel effects ( $p$ values $>$ .1; see Figure 2C and D), along with the Dom by AmbType, $F(1,19)=2.72$, and Rel by AmbType, $F(1,19)=2.16$, interactions were not significant.

\section{EXPERIMENT 1: DISCUSSION AND RATIONALE FOR EXPERIMENT 2}

The Experiment 1 RT data replicate the reversed priming effects obtained in previous studies (Elston, 1996; Wagner, 1996). This reversed priming suggests that the two translations of a homonym are connected by inhibitory connections in the mental lexicon, as in Figure 1. In support of this idea, the present experiment also obtained ERP N200 effects. The ERP effects are very early, between 100 and $200 \mathrm{msec}$ poststimulus onset, and 


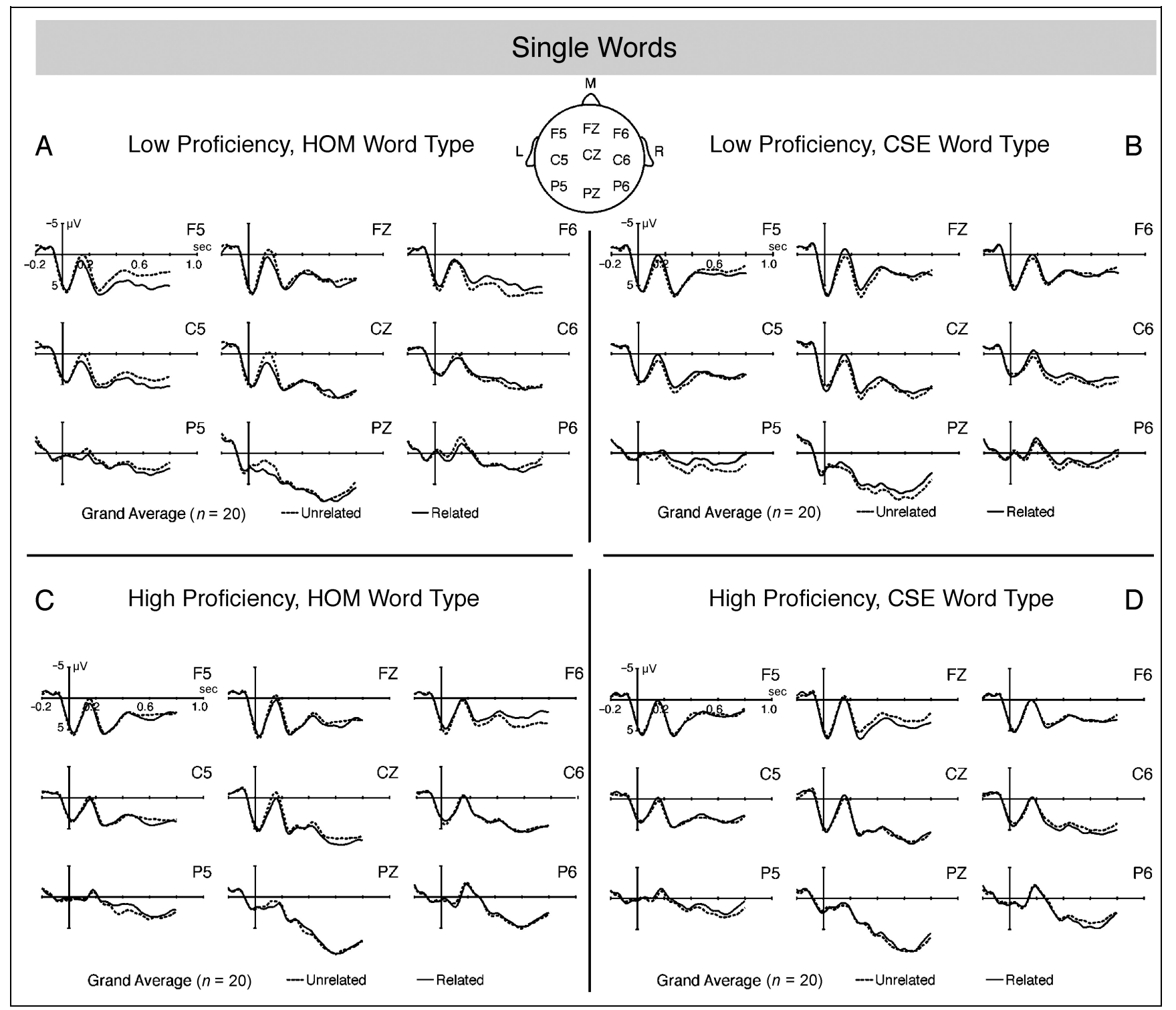

Figure 2. Experiment 1 (single-word experiment) ERP data. High- versus low-proficiency group, ERPs elicited by critical targets in the HOM and CSE conditions at selected electrode sites. Waveforms show the average for related (solid line) and unrelated (dotted line) targets from $200 \mathrm{msec}$ before stimulus onset up to $800 \mathrm{msec}$ poststimulus onset. For the low-proficiency group (A and B), significant modulations of the ERP were observed between 100 and $200 \mathrm{msec}$ poststimulus (priming for HOM in A, reversed priming for CSE in B), whereas for the high-proficiency group (C and D), no significant ERP modulations were observed.

were found in the absence of N400 effects. The behavioral effects, in contrast, were obtained at lexical decision, at around $795 \mathrm{msec}$ poststimulus onset. Therefore, we suggest that ERP and RT measures tap different processing stages and processes: the ERP effects probably reflect orthographic processing, whereas the RT effects may reflect a postlexical access relatedness checking procedure (cf. Keatley, Spinks, \& De Gelder, 1994; Keatley \& De Gelder, 1992; De Groot \& Nas, 1991; Neely, 1991; Neely, Keefe, \& Ross, 1989; De Groot, 1984). In the absence of $\mathrm{N} 400$ effects, it seems most reasonable to assume that although the prime and target were not related semantically, participants were aware of some "relatedness" at lexical decision.
Faster RTs were made to the more frequent CSE words than to less frequent HOM words, and there was also a tendency toward a dominance effect in the priming observed in the RTs, both effects not present in the ERPs. Thus, tentatively, we suggest that early effects in the ERP may be more sensitive to multiple meanings (i.e., the differences in priming between the CSE and HOM word types), whereas later processing may be more sensitive to dominance and/or frequency information. This assumption is also supported by the homonym processing literature in the L1 (e.g., Seidenberg, Tanenhaus, Leiman, Bienkowski, 1982; Onifer \& Swinney, 1981; Swinney, 1979) and in the L2 (Elston-Güttler \& Friederici, 2005; Frenck-Mestre \& Prince, 1997) that 
has reported early multiple activation of meanings followed later by context or dominance (relative frequency) effects. As the N200 time window is at 100 200 msec and the RTs are at over 700 msec poststimulus, the differences observed in the two measures may reflect this previously reported processing time course.

The RT data suggest that at the single-word level, dominance plays an important role for both proficiency groups, that is, only dominant targets resulted in reversed priming, but as suggested above, only later in processing. If the RTs in fact reflect a relatedness checking procedure, then it is plausible that after reading pine, then seeing jaw (the more dominant meaning from German), participants responded slower because pine and jaw are competitors corresponding to the word Kiefer. Because the reversed priming was not obtained the other way around, that is, for the jaw-pine pair, we assume that the link from the German homonym to the more dominant meaning is stronger (i.e., the link from Kiefer to jaw in Figure 1), resulting in stronger activation of the more dominant meaning, hence a more profound awareness that the words in the pair pine-jaw are in some way related. It appears that this dominance information only plays a role at this later behavioral processing stage.

The ERP data, in contrast, show very early modulations between 100 and $200 \mathrm{msec}$ in different directions for the HOM and CSE word types, but only for the lowproficiency group. As discussed in the Introduction and above, we assume that the early modulation of the ERP reflects word form-level inhibitory connections between the two translations of a homonym. It is not entirely clear why the HOM word type targets resulted in a normal priming pattern, whereas CSE words showed the predicted reversed priming pattern. One speculation is that the process of spreading activation may be different for the HOM words: the HOM word primes may have activated the L1 word form meaning faster, as they were not ambiguous in English. With this faster L1 word activation, it is conceivable that the inhibitory link between homonym meanings required to cause interference (between pine and jaw in Figure 1) was not yet functional in the N200 time window for HOM words. This would mean that instead of the prime inbibiting activation of the target, the prime activation actually facilitated the target. The crucial result of Experiment 1, however, is that only the low-proficiency group showed any early ERP modulations at all. It may be the case that an inhibitory link was at play in the case of CSE words, although it was not yet in operational for the HOM words. In either case, irrelevant L1 lexical representations were active in order for effects in both directions to occur.

The high-proficiency group, in contrast, showed no significant ERP modulations. This goes along with our initial assumption that lower proficiency learners (cf. the
RHM, Kroll \& Stewart, 1994) have a stronger L1-L2 interface at the word form level, although we can also account for our data in terms of viable ability to deal with task demands. In terms of the BIA+ model (Dijkstra \& Van Heuven, 2002), we assume here that language proficiency might affect the decision criteria in the "task/ decision" system without actually affecting the wordidentification system that involves semantic context effects. Here, high-proficiency learners can probably use nonlinguistic cues more effectively than less proficient language users. Thus, in the all-L2 word list, the high-proficiency group utilized a task execution whereby L1 translations were irrelevant: Only later on in processing, at RTs, did the L1 activations have time to create awareness of relatedness between items. In contrast, the low-proficiency group could not set the task execution as well, and L1 translations were active both at the N200 and in the RTs.

However, what happens when processing of translated homonyms occurs in context? In this case, proficiency can play a role in how learners deal with task demands, but also in differential effects of semantic context, which is part of the actual word-identification system in the BIA+ model (Dijkstra \& Van Heuven, 2002). With the exception of a handful of studies (Elston-Güttler, 2000; Altarriba, et al., 1996; Elston, 1996; Wagner, 1996), the effects of semantic sentence context have not been as widely studied (De Bruijn, et al., 2001, for instance, used word triplets, but not full sentences). In Experiment 2, the same material was presented to both high- and low-proficiency groups, but this time in sentence contexts. Now we aim to find out whether the combined effects of better task control and semantic context will mean that the high-proficiency group will no longer show any RT or ERP effects. In contrast, if less proficient learners showed reversed RT priming of translated homonyms in sentence context in previous studies (Elston, 1996; Wagner, 1996), will the low-proficiency group continue to show the RT interference effects, and possibly the N200 ERP effects, once semantic contexts are introduced?

\section{EXPERIMENT 2: BEHAVIORAL DATA}

\section{Analysis of Accuracy}

See Table 4 for error data and Table 6 for a summary of significant results. In the analysis of error data over both proficiency groups, there were significant main effects of AmbType, $F(1,32)=16.32, p=.0003$, with HOM targets with $11.0 \%$ errors and CSE with $8.0 \%$ errors, and of Dom, $F(1,32)=43.85, p<.0001$, with dominant targets yielding an error rate of $6.8 \%$ and subordinate targets a rate of $12.5 \%$. Neither AmbType nor Dom was qualified by Group (all $p$ values $>.1$ ). All other critical main effects and interactions were not significant (all $p$ values $>$ .1). The error data indicate more accurate responses 
Table 6. Experiment 2: Summary of Significant Main Effects, Interactions, and Step-Down Analyses for Accuracy, RT, and ERP Data

\begin{tabular}{|c|c|c|c|c|c|c|c|c|}
\hline \multicolumn{3}{|c|}{ Accuracy } & \multicolumn{3}{|c|}{$R T$} & \multicolumn{3}{|c|}{ ERP Time Window, 100-250 msec } \\
\hline $\operatorname{Factor}(s)$ & $d f$ & F Value & $\operatorname{Factor}(s)$ & $d f$ & $F$ Value & Factor(s) & $d f$ & $F$ Value \\
\hline AmbType & 1,32 & $16.32 * *$ & Rel & 1,32 & $9.69 * *$ & Rel & 1,32 & $4.35^{*}$ \\
\hline \multirow[t]{9}{*}{ Dom } & 1,32 & $43.85 * * * *$ & AmbType & 1,32 & $7.24 *$ & Rel $\times$ Dom & 1,32 & $4.97 *$ \\
\hline & & & Dom & 1,32 & $19.60 * * *$ & Dominant Rel & 1,32 & $3.97^{+}$ \\
\hline & & & Rel $\times$ Group & 1,32 & $5.01 *$ & Rel $\times$ SROI & 6,192 & $2.16^{*}$ \\
\hline & & & High Group Rel & 1,16 & 0.59 ns & Left Frontal Rel & 1,32 & $17.06 * * *$ \\
\hline & & & Low Group Rel & 1,16 & $11.20 * *$ & Left Central Rel & 1,32 & $7.27 *$ \\
\hline & & & & & & Rel $\times$ Group & 1,32 & $3.46^{+}$ \\
\hline & & & & & & High Group Rel & 1,16 & $0.02 n s$ \\
\hline & & & & & & Low Group Rel & 1,16 & $9.09 * *$ \\
\hline & & & & & & Rel $\times$ AmbType $\times$ Dom $\times$ SROI & 6,192 & $2.45^{*}$ \\
\hline
\end{tabular}

F values and significance levels are listed for significant main effects and interactions in the omnibus analysis on Error, RT, and ERP data, along with significant statistics in relevant step-down analyses. All effects not listed in the table are not significant $(p$ values $>.1)$.

$* p<.05$.

$* * p<.01$

$* * * p<.001$.

$* * * * p<.0001$.

$+p<.1$.

to dominant targets than to subordinate targets, and to CSE items than to HOM items, independent of proficiency group.

\section{Analysis of RTs}

See Table 4 for RTs and SDs and Table 6 for a summary of significant results. In the analysis of correct RTs over high- and low-proficiency groups, there was a main effect of Rel, $F(1,32)=9.69, p=.004$, that was qualified by Group, $F(1,32)=5.01, p=.032$. Other significant main effects included Dom, $F(1,32)=19.60, p<.001$, with dominant targets (785 msec) faster than subordinate ones (828 msec), and AmbType, $F(1,32)=7.24$, $p=.011$, with HOM targets (821 msec) slower than CSE ones (792 msec). Neither Dom nor AmbType was qualified by Group ( $p$ values $>.1)$. All other interactions were not significant (all $p$ values $>.1$ ). In the by-Group analyses performed to follow up the omnibus interaction, the low group showed a significant main effect of Rel, $F(1,16)=11.20, p=.004$, with related targets (823 msec) slower than unrelated targets (777 msec), whereas the high group showed a nonsignificant main effect of Rel, $F(1,32), F(1,32)=.59$, with related targets (816 $\mathrm{msec})$ responded to slower than unrelated targets (806 msec; see Table 4). Overall, the data suggest generally faster processing of dominant meanings and CSE words, regardless of the level of proficiency, and comparably fast RTs across groups. Most crucial to our research question is that only the low-proficiency group exhibited reversed RT priming.

\section{EXPERIMENT 2: ELECTROPHYSIOLOGICAL DATA}

\section{Visual Inspection}

See Figure 3 for Experiment 2 ERP data. Based on visual inspection over conditions and groups, the ERP waveforms were comparable to those obtained in Experiment 1, but the early negativity observed in the sentence version peaked at $175 \mathrm{msec}$ and extended to slightly beyond $200 \mathrm{msec}$. For this reason, the N200 time window analyzed was 100-250 msec after target onset. As main effects of Rel and interactions with Rel between 300-500 msec and 500-700 msec were not significant (all $p$ values $>.1$ ), only the N200 time window is reported below.

\section{0-250 msec}

See Table 6 for a summary of significant results. In this analysis, there was a significant main effect of Rel, $F(1,32)=4.35, p=.045$, which indicated a reversed priming effect. All other main effects were not significant (all $p$ values $>.1$ ). The Rel effect was also qualified by Dom, $F(1,32)=4.97, p=.033$, and by the factor scalp regions of interest (SROI), $F(6,192)=2.16, p=.049$, and there was an interaction between Rel and Group 


\section{Words in Sentence Context}

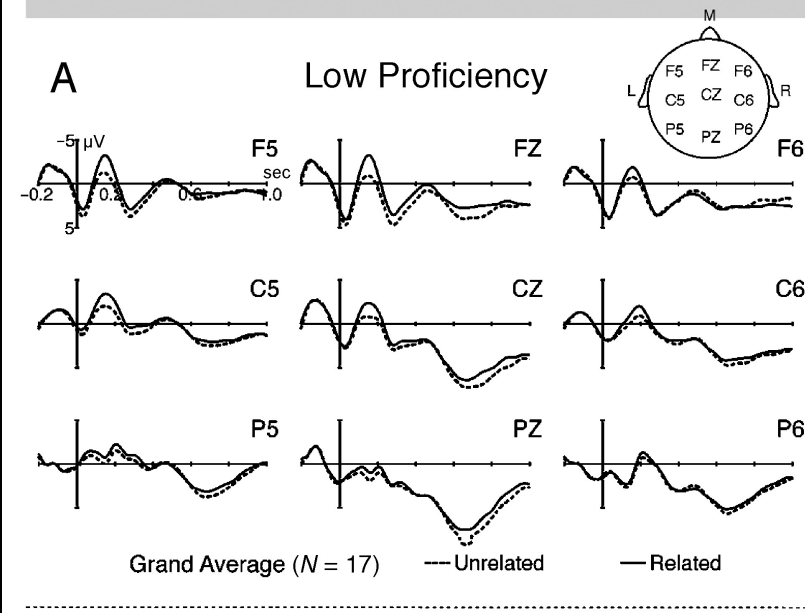

B
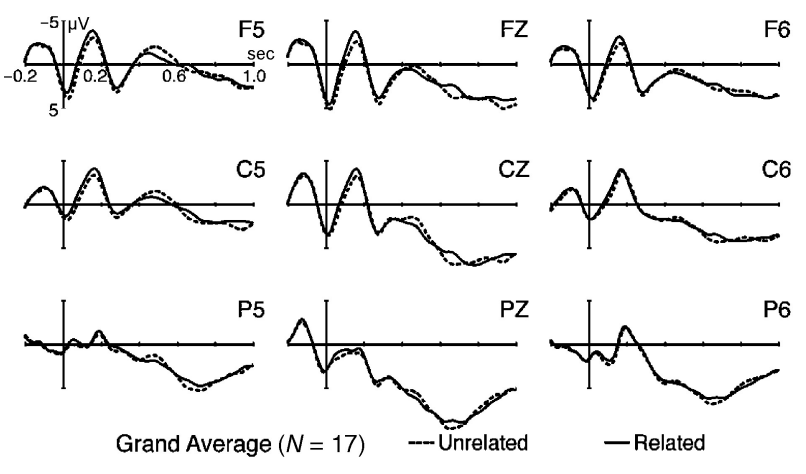

C Native Speakers
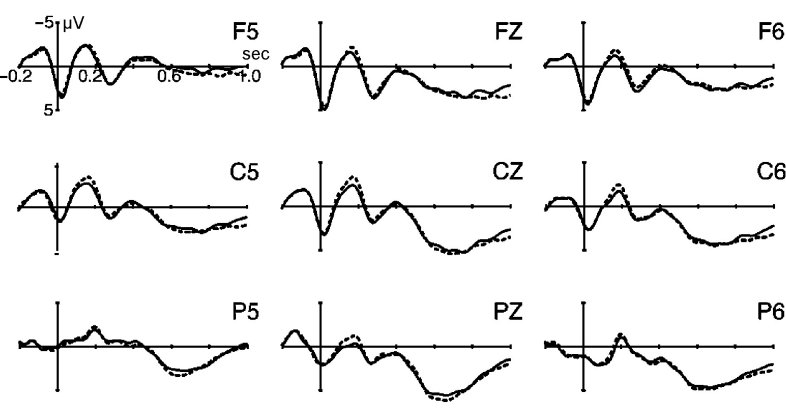

Grand Average $(N=17) \quad$----Unrelated -Related

Figure 3. Experiments 2 and 3 (sentence experiment) ERP data. A and B show high- versus low-proficiency groups, and $\mathrm{C}$ shows the native English speaker control group. Waveforms show the average for related (solid line) and unrelated (dotted line) targets from $200 \mathrm{msec}$ before stimulus onset up to 1000 msec poststimulus onset. The low-proficiency group (A) shows significant reversed priming in the ERP between 100 and 250 msec poststimulus, whereas no such modulation is observed in the high-proficiency group (B) or in the English natives (C).

that approached significance, $F(1,32)=3.46, p=.072$. There was also a significant interaction between Rel, AmbType, Dom, and SROI, $F(6,192)=2.45, p=.026$. To explore the interactions, analyses by Group, SROI, Dom, and AmbType were performed.
When analyzed by Group, the low-proficiency participants showed a significant main effect of Rel, $F(1,32)=9.09, p=.008$, with related targets more negative $(-0.60 \mu \mathrm{V})$ than unrelated targets $(-0.02 \mu \mathrm{V})$, thus demonstrating reversed priming (see Figure $2 \mathrm{~A}$ ). In contrast, the high-proficiency participants showed a nonsignificant main effect of Rel, $F(1,32)=.02$ (see Figure $2 \mathrm{~B}$ ), whereas the interaction between Rel and Dom, $F(1,32)=2.79, p=.060$, approached significance. However, analysis by Dom in the high group showed nonsignificant effects for subordinate, $F(1,16)=$ 2.74 , and dominant, $F(1,16)=2.40$ targets.

When analyzed by the factor SROI over proficiency groups, there was an increased negativity for related targets or a reversed priming effect in $\mathrm{LF}, F(1,32)=$ $17.06, p=.001$, and LC electrode sites, $F(1,32)=7.27$, $p=.011$. Effects of Rel in other regions of interest were not significant, $F(1,32)=0.15-2.47$. Although there was no significant interaction between Group, Rel, and SROI, in light of our hypotheses, it is important to note that there were interactions between Group and Rel in the following regions of interest: LC, $F(1,32)=4.27, p=$ .047 ; LP, $F(1,32)=4.43, p=.043$; and ML, $F(1,32)=$ $4.11, p=.051$. In a post-hoc analyses of Rel effects by SROI split by Group, the high-proficiency group showed no significant effects in any region of interest: $F$ s $<1.0$, except $F(1,32)=2.39$ for LF. In contrast, the lowproficiency group showed significant Rel effects reflecting reversed priming in LC, $F(1,16)=11.18, p=.004$; $\mathrm{LF}, F(1,16)=17.46, p=.001 ; \mathrm{LP}, F(1,16)=4.55, p=.049$; and ML, $F(1,16)=6.38, p=.023$, with borderline significance at RF, $F(1,16)=4.38, p=.053 ; \mathrm{RP}, F(1,16)=3.71$, $p=.072 ;$ and $\mathrm{RC}, F(1,16)=2.37$.

In the analyses by Dom and AmbType, all main effects and interactions involving the factor Rel were not significant (all $p$ values $>.1$ ), except in the by-Dom analysis the dominant meanings showed a borderline Rel effect, $F(1,32)=3.97, p=.055$, with related targets less negative $(-0.48 \mu \mathrm{V})$ than unrelated targets $(-0.63 \mu \mathrm{V})$. The dominant meanings also showed a borderline interaction between Rel and Group, $F(1,32)=3.61, p=$ .066 , because the high group showed a nonsignificant Rel effect, $F(1,16)=2.40, p=.141$ (related targets $-0.42 \mu \mathrm{V}$, unrelated targets $-1.04 \mu \mathrm{V}$ ), in the opposite direction as the low group's effect for dominant targets, $F(1,16)=1.22, p=.286$ (related targets $-0.54 \mu \mathrm{V}$, unrelated targets $-0.22 \mu \mathrm{V}$ ). The omnibus interactions reflect that the high groups' nonsignificant effects for dominant meanings were facilitatory, whereas the low groups' significant overall effects were reversed priming.

\section{EXPERIMENT 2: DISCUSSION AND RATIONALE FOR EXPERIMENT 3}

Experiment 2 set out to examine the role of proficiency on the combined aspects of all-L2 task and semantic context in processing translated homonyms. We aimed 
to determine whether the early ERP effects obtained in Experiment 1 in the low-proficiency group would disappear once sentence context was introduced; this was not the case. The low-proficiency learners showed a strong overall reversed priming effect from 100 to $250 \mathrm{msec}$, with a left frontal scalp distribution similar to effects obtained in go/no-go tasks discussed in the Introduction. Thus, the distribution pattern of the present N200 effect suggests that inhibitory mechanisms may be at play in the L1 influence on the L2. Even though each prime-target pair was preceded by a sentence that clearly made the other translation irrelevant, the inhibitory links between translations affected processing for lower proficiency learners very early in processing.

For the low-proficiency group, influence from the L2 was also observed at the later processing phase reflected in the RTs. The reversed priming effect was obtained only for the low-proficiency group, despite comparable overall speed and accuracy between the high and low groups. Similarly, fast processing of targets by lowproficiency learners was also obtained in Kotz and Elston-Güttler (2004), where it was argued that RT speed alone does not necessarily reflect native-like processing. In both experiments, fast RTs in conjunction with nonnative patterns in the ERP suggest that low-proficiency learners may process words in a more shallow, "lexical" manner than high-proficiency learners do. The RT effect over both dominant and subordinate word types suggests that the presence of sentence contexts diminished the role of the stronger link between the activated German homonyms and the dominant meanings. This goes along with ERP evidence that in homonym processing in L1 sentence contexts, dominance plays a minor role in processing, especially for less skilled (low reading span) participants (Gunter, Wagner \& Friederici, 2003). The ERP and RT effects observed by low-proficiency learners in sentence context make a strong case for a highly integrated lexicon linked at the word form level and a fundamentally nonselective word-recognition system.

The high-proficiency learners no longer showed behavioral effects in Experiment 2 and therefore appear to have not been influenced at all by L1 activations during L1 processing. This implies in the BIA+ model (Dijkstra \& Van Heuven, 2002) that even though word recognition is fundamentally nonselective, proficiency may interact with the task/decision system, but also with semantic context that affects the word-identification system. High proficiency appears to enable not only increased ability to deal with task demands, but also improved ability to use semantic context in an effective way. The results of the low-proficiency group in Experiment 2 also suggest that effective task control is a prerequisite for effective use of semantic context: Despite the very same "double" context the high group had, the low group still showed RT and ERPs effects in an all-L2 task in sentence context. This means that only with the combination of an all-L2 task demand, biasing semantic sentence context, and high proficiency can learners achieve native-like lexical processing unaffected by the L1. To pursue this argument, we tested a group of native English speakers with no knowledge of German on the same material as in Experiment 2. We predict no relatedness effects for either CSE or HOM word types, but possibly slower overall RTs or a more negative amplitude in the ERP for CSE words due to the ambiguity in English.

\section{EXPERIMENT 3: BEHAVIORAL DATA}

\section{Analysis of Accuracy}

See Table 4 for error data. In the analysis of errors for the native English speakers, there was a marginally significant main effect of Dom, $F(1,15)=4.11, p=$ .061 , with fewer errors for dominant targets (5.2\%) than for subordinate ones (4.0\%). There was also a borderline Dom by Rel interaction, $F(1,15)=4.08, p=.062$, reflecting a nonsignificant difference in accuracy over related and unrelated conditions, $F(1,15)=2.58$, for subordinate targets only.

\section{Analysis of RTs}

See Table 4 for RTs and SDs. In the analysis of correct RTs in the native speaker group, there were no significant main effects or interactions (all $p$ values $>.1$; see Table 4). Although response times to related dominant targets were numerically faster than to dominant unrelated targets, this difference was not significant, $F(1,15)=1.26$.

\section{EXPERIMENT 3: ELECTROPHYSIOLOGICAL DATA}

\section{0-250 msec}

See Figure 3 for Experiment 3 ERP data. In the visual inspection, the waveform profile was comparable to that obtained in Experiment 2, but with a smaller early N200 component and no obvious modulation of it dependent on Rel. The main effect of Rel was not significant in the early time windows of 100-250, 300-500, and 500 $700 \mathrm{msec}$, respectively (all $p$ values $>.1$ ). In the 100- to 250 -msec time window, there was a significant main effect of AmbType, $F(1,15)=5.10, p=.039$, with CSE targets showing a generally more negative-going wave $(-0.88 \mu \mathrm{V})$ than the HOM targets $(-0.42 \mu \mathrm{V})$, probably due to the ambiguity in English of the CSE items. This more negative amplitude for the CSE words is not surprising in light of our assumption discussed earlier that the multiple meanings of CSE words make processing more difficult only early on before frequency or 
dominance can play a more profound role. The native speaker data reveal null results with regard to the factor Rel in both the early ERP and later behavioral domains. This indicates that native-like processing is reflected by the absence of modulations in the ERP and reversed priming in the RTs that we have argued indicate L1 influence.

\section{GENERAL DISCUSSION}

In the current set of experiments, we report a gradation of influence from the L1 on the L2 during lexical processing: This influence is modulated by early ERP versus later behavioral effects, L2 proficiency level, and whether an all-L2 lexical decision task is conducted as single-word trials or in sentence contexts. We have investigated the activation of the L1 in a way that departs from the interlingual homograph literature by looking at competing activation of L1 homonym translations. Low-proficiency learners showed both early reversed priming N200 effects and later RT effects in both single word (Experiment 1) and sentence context tasks (Experiment 2). In contrast, the high-proficiency group showed reversed priming RT effects only in the single-word task (Experiment 1), but once sentence context was introduced (Experiment 2), they showed no effects whatsoever, effects comparable to native English speaker results on the same task (Experiment 3). The ability on the part of highproficiency learners to apparently "block out" L2 influence may be explained in terms of the combined influence of the task/decision system and the wordidentification system in the BIA+ model (Dijkstra \& Van Heuven, 2002). On the other hand, a developmental interpretation of the RHM (Kroll \& Stewart, 1994) may explain why the lower proficiency learners have trouble controlling L1 influence, and more specifically, why such influence is reflected by the N200 as opposed to the N400 ERP component. The effects obtained may also suggest some functional correlates of the N200 component.

The BIA+ model of the bilingual word-recognition system (Dijkstra \& Van Heuven, 2002) can account for a range of phenomena in language control by assuming systems that control nonlinguistic (task) context and semantic context separately. Grainger and Dijkstra (1992) first assumed the three representational levels of letter, word, and language nodes. This allows for access to both the L1 and L2 in parallel, but language nodes are activated to different degrees depending on language context: The language node is activated depending on the prime, resulting in "preactivation" of same-language word nodes. In the version of the BIA model in Dijkstra, Van Jaarsveld, and Brinke (1998), it was proposed that the language node could be activated not only from the bottom-up, but also from the top- down from sources external to the system. This idea is similar to language task schemas in Green's (1998) inhibitory control (IC) model, where a task schema can regulate the outputs from the semantic systems by changing the degree to which a lexical item's language tag is activated. The IC model (Green, 1998) and the BIA + model (Dijkstra \& Van Heuven, 2002) could, in theory, accommodate the role of proficiency by assuming that a learner's level of proficiency affects a "default" setting of, or the ability to effectively set, the language task schema in the IC or the task/decision system in the $\mathrm{BIA}+$. As discussed, less proficient learners cannot adjust to the all-L2 task as well in single-word tasks, and when sentence context is introduced, they have difficulty utilizing the biasing context information effectively. More extensive knowledge of the L2 apparently means that tasks can be better regulated and that semantic context can be more effectively used. This does not imply that the bilingual word-recognition system is selective for high-proficiency learners, as presumably high and low learners operate in a similar system. Rather, the combined influences of proficiency, all-L2 task demands, and semantic context constraints mean that very proficient learners modulate the system to the point where L1 influences are not detectable and comparable to native electrophysiological and behavioral patterns. The fact that the high group showed later RT effects in the single-word version support this idea: If the system is fundamentally nonselective, then we would expect some L1 influence in single-word processing, but once the additional semantic context enters in, the threshold for L1 activation decreases further. In the case of the low group, it would seem as if the modulation of the word-recognition system depends on adequate task control, as they did not "benefit" from the addition of semantic context. The implications of this for the IC and BIA+ models should be considered in future experiments.

The low-proficiency learners may also have particularly strong word form (translation) links in the L1-L2 lexicon, regardless of task requirements. The RHM (Kroll \& Stewart, 1994) implies more reliance on these links for lower proficiency learners and, furthermore, assumes that the interface between the L1-L2 lexicons is indeed at the word form level. In all experiments reported in this study, we did not observe modulations of the N400. Rather, we observed earlier effects between 100-200/ 100-250 msec poststimulus. In light of our discussion of the N200 and also the assumption that the N400 reflects semantic processing, we argue that the effects obtained in our study are not truly semantic in nature, but a reflection of linkages (and inhibitory connections) between word forms. The BIA+ and implicitly the RHM assume such word-form level involvement in the control system, but in the IC, the lemma level is assumed to be the locus of control (cf. Green, 1998). Here our data suggest word form activation from the $\mathrm{L} 2$, but this does 
not imply that the bilingual control system operates solely on this level. The effects in this study support both of the interpretations of the N200 that we initially entertained, that is, orthographic processing, and alternatively, inhibition processing, especially as the distribution of the effect in Experiment 2 was left and frontal, in line with previous studies on inhibition processing (Thorpe et al., 1996; Eimer, 1993; Jodo \& Kayama, 1992; Kok, 1986). Although these interpretations of the N200 remain somewhat speculative, the N200 has nevertheless provided important insight into the differential influence of $\mathrm{L} 1$ word activation during $\mathrm{L} 2$ processing as a function of L2 proficiency.

\section{METHODS}

\section{Participants}

For Experiments $1(n=40 ; 36$ women $)$ and $2(n=$ 34; 24 women), students from the University of Leipzig volunteered in the experiment and were paid for participation. All Experiment 1 and 2 participants were native speakers of German who had acquired English after the age of 11 in a formal school setting and were assigned to the two language conditions, highproficiency and low-proficiency, according to a language questionnaire and postexperiment testing. (See Table 1 for data on Experiment 1 and 2 participants.) In Experiment 3, participants ( $n=17$; 10 women) were native English speakers who were visitors to the University of Leipzig or the Free University in Berlin and were paid for their participation. These participants also filled out the language questionnaire, but only to ensure that they fulfilled the prerequisite for participation, which was extremely little or no knowledge of the German language. This prerequisite was thought necessary to ensure that the English speakers were not influenced by potential knowledge of German. Experiment 3 participants had a mean age of 22 years (range, 19-25 years). Participants in all experiments were right-handed and had normal or corrected-to-normal vision.

\section{Selection of Stimuli}

The two conditions were as follows: (1) HOM words where both translations are unambiguous in English, and (2) CSE words, where one English translation was also ambiguous (as in duty in the example in Table 2). HOM and CSE were separated by the factor AmbType; as the items naturally fell into these subcategories, it seemed possible that ambiguity of the prime in English may affect processing, and the CSE English translations were generally more frequent than the HOM items (see Table 3 for frequencies).

The dominant or subordinate meanings of German homonyms and their translations in English were determined by randomized questionnaires in German (re- ported in Elston-Güttler, 2000) administered to 96 native German speakers with advanced knowledge of English. The participants were asked to indicate the first, second, and subsequent meanings they thought of when they read a given homonym and to write down the best translation they could think of next to their definition given in German. One hundred fourteen German homonyms included in the German questionnaire (participants rated half) were generated as potential items by reviewing published lists of German homonyms (Weber, 1996; Möller, 1992). English translations chosen were those listed most often for a particular meaning and were checked against Wagner (1996). German homonyms with noun-noun ambiguities were preferred, but other types (noun-verb, verb-verb, adjective-adjective) were also chosen and balanced carefully on presentation lists.

For Experiments 2 and 3, sentence contexts preceding the prime were also constructed. One sentence was written to support the dominant meaning, whereas another supported the subordinate meaning of the German homonym. Targets always reflected the other contextually irrelevant meaning of the German homonym (see Table 2 for examples). Care was taken to ensure that the sentences read well with both the test and the control primes. Thus, control and test primes (sentence-final words) were word length and frequency matched on an item-by-item basis and were often semantically related (i.e., pine as a test word, oak as the control). In all cases, the control word never appeared as a translation of the German homonym from the norming study. Sentences preceding pseudowords and filler sentences were constructed to mirror the critical sentences syntactically and with regard to word count. Three native speakers of English reviewed all sentences for semantic coherence, and three intermediate German learners of English reviewed the sentences for any unknown words or constructions. The four sentences corresponding to an item were then balanced on two presentation lists so that no targets were repeated (e.g., conditions 1 and 4 in one list, 2 and 3 in the other) and so that prime and target letter length and frequency were matched. (See Table 3 for sentence word count means and prime and target data.) Note that the frequencies reflect the English words used in the experiment, not the relative dominance of the German homograph meanings determined by the questionnaire data.

Each presentation list consisted of 480 trials composed of 80 critical CSE trials and 80 critical HOM trials, 160 filler word trials, and 240 pseudoword trials divided into 12 miniblocks of 40 trials each. The word-pseudoword ratio was 1:1 and the related-unrelated for word trials was 1:4. Pseudoword targets (e.g., reckop) were designed to look like critical targets in syllabic structure and letter length and abided by legal English orthography and phonology. 


\section{Procedure}

Testing was carried out in a soundproof and electrically shielded chamber. Participants sat on a comfortable chair facing a computer monitor from a distance of $1.2 \mathrm{~m}$. After performing a practice session of 20 trials that was repeated until accuracy reached $80 \%$, the experimental session of 12 miniblocks was conducted. Half the subjects answered with their left index finger for YES (word) and their right index finder for No (not a word) on a three-button panel (the middle button was used to continue after breaks), and the other half did the opposite. Subjects were instructed to make a lexical decision for the target as accurately and as quickly as possible.

In Experiment 1, each trial consisted of an eye fixation cross displayed for $200 \mathrm{msec}$, presentation of the prime for $200 \mathrm{msec}$ in the center of the screen, a blank screen for $200 \mathrm{msec}$, presentation of the target until lexical decision was made (cutoff of $3000 \mathrm{msec}$ ), followed by an 800 -msec intertrial interval. For Experiments 2 and 3, the trial began with the presentation of a sentence (excluding the final word) slightly to the left of the screen, and participants were instructed to read the sentence and then indicate YES when ready to proceed. At this point, the trial proceeded in the same way as for the single-word version, but to minimize eye movements, prime and target appeared at the point of eye fixation at the end of the sentence that had just disappeared (approximately $10^{\circ}$ of visual angle to the right). After every 40-trial miniblock, a secondary task was included in the experiment to ensure that subjects were actually paying attention to the primes (and sentences in Experiments 2 and 3). In this task, MEMORY RECALL appeared on the screen, followed by six words (or six full sentences for Experiments 2 and 3), three of which appeared in the previous block and three that appeared nowhere in the experiment. Subjects had to press the YES button if they remembered the word or sentence, and the NO button if not. After the experiment, subjects filled out a post-test that included all critical words, and they were asked to mark any words whose meaning they did not know. See Table 1 for results of the memory recall and vocabulary tests.

\section{ERP Recording}

Sixty-four EEG channels were recorded from the scalp by means of $\mathrm{Ag} / \mathrm{AgCl}$ electrodes attached to an elastic cap: NZ, FP1, FPZ, FP2, AF7, AF3, AFZ, AF4, AF8, F9, F7, F5, F3, FZ, F4, F6, F8, F10, FT9, FT7, FC5, FC3, FCZ, FC4, FC6, FT8, FT10, T9, T7, C5, C3, CZ, C4, C6, T8, T10, TP9, TP7, CP5, CP3, CPZ, CP4, СР6, TP8, TP10, P9, P7, P5, P3, PZ, P4, P6, P8, P10, PO7, PO3, POZ, PO4, PO8, O1, OZ, O2, A1, A2. Each EEG channel was amplified with a band pass from DC to $30 \mathrm{~Hz}$ with a digitization rate of $250 \mathrm{~Hz}$. C2 served as a ground electrode. All electrodes were referenced to the left mastoid (X1) and re-referenced to linked mastoids off-line. To control for eye movement artifacts, horizontal and vertical electrooculograms (EOG) were recorded. Electrode impedances were kept below $5 \mathrm{k} \Omega$. Trials with eye blinks and artifacts, along with trials corresponding to words that subjects did not know in the post-test, were removed from the raw data set on a subject-by-subject basis before averaging the data for each subject.

\section{RT and ERP Data Analyses}

Mean RTs for correct responses and percent correct were calculated for each subject, and outlier data points were removed if they fell above or below $2.5 S D$ of the participant mean. Individual EEG recordings were scanned for artifacts, and separate ERPs for each condition at each electrode site were averaged for each participant. In all experiments, the critical group comparisons of the ERP data were quantified for correct responses by calculating amplitudes relative to a $100-\mathrm{msec}$ prestimulus baseline in the latency window of 100 to $200 / 250$ msec based on visual inspection of the data. In all experiments, the $2 \times 2 \times 2 \times 2$ analysis of variance (ANOVA) for repeated measures described in Experiment 1 was conducted. In all ERP analyses, the factor SROI was also included. Each SROI defined a critical region of six scalp sites: left frontal (LF): F7 F5 F3 FT7 FC5 FC3; right frontal (RF): F8 F6 F4 FT8 FC6 FC4; left central (LC): T7 C5 C3 TP7 CP5 CP3; right central (RC): T8 C6 C4 TP8 CP6 CP4; left posterior (LP): P7 P5 P3 PO7 PO3 O1; right posterior (RP): P8 P6 P4 PO8 PO4 O2 and the midline (ML): FZ FCZ CZ CPZ PZ POZ. Significant main effects and interactions were followed up by simple effects analyses and pair wise comparisons. The Geissser-Greenhouse correction (Geisser \& Greenhouse, 1959) was applied to all repeated measures with greater than one degree of freedom. Given that main effects of topographical factors are not of interest for the hypotheses posed, statistical analyses only report interactions of topographical factors with condition effects. Exact $F$ and $p$ values are reported for significant data, and $F$ values are reported for nonsignificant data.

\section{Acknowledgments}

The authors thank Ina Koch and Sylvia Stasch for data acquisition and subject recruitment and Suzanne Wagner for her input and norming data. An early behavioral version of this study was part of the first author's $\mathrm{PhD}$ dissertation done under the supervision of John Williams at the Research Centre for English and Applied Linguistics, University of Cambridge.

Reprint requests should be sent to Kerrie E. Elston-Güttler, Max Planck Institute for Human Cognitive \& Brain Sciences, Neurocognition of Language, P.O. Box 500, 355 Stephanstraße 1a, D-04103 Leipzig, Germany, or via e-mail: guettler@cbs. mpg.de. 


\section{Note}

1. The experiment in Elston-Güttler (2000) was part of a long battery of experiments and may have been affected by additional task and/or practice effects. Elston (1996), Wagner (1996), and the present study, however, were presented as single experiments with tightly controlled task demands.

\section{REFERENCES}

Altarriba, J., Kroll, J. F., Scholl, A., \& Rayner, K. (1996). The influence of lexical and conceptual constraints on reading mixed-language sentences: Evidence from eye fixations and naming times. Memory \& Cognition, 24, 477-492.

Baayen, H., Piepenbrock, R., \& Van Rijn, H. (1993). The CELEX lexical database (CD-ROM). Philadelphia, PA: University of Pennsylvania, Linguistic Data Consortium.

Balota, D. A., \& Paul, S. T. (1996). Summation of activation: Evidence from multiple primes that converge and diverge within semantic memory. Journal of Experimental Psychology: Learning, Memory, and Cognition, 22, 827-845.

Beauvillain, C., \& Grainger, J. (1987). Accessing inter-lexical homographs: Some limitations of language-selective access. Journal of Memory and Language, 26, 658-672.

Bentin, S., Mouchetant-Rostaing, Y., Giard, M. H., Echallier, J. F., \& Pernier, J. (1999). ERP manifestations of processing printed words at different psycholinguistic levels: Time course and scalp distribution. Journal of Cognitive Neuroscience, 11, 235-260.

Bijeljac-Babic, R., Biardeua, A., \& Grainger, J. (1997). Masked orthographic priming in bilingual word recognition. Memory \& Cognition, 25, 447-457.

Chen, H. C., \& Ho, C. (1986). Development of Stroop interference in Chinese-English bilinguals. Journal of Experimental Psychology: Learning, Memory, and Cognition, 12, 397-401.

Cheung, H., \& Chen, H. C. (1998). Lexical and conceptual processing in Chinese-English bilinguals: Further evidence for asymmetry. Memory and Cognition, 26, 1002-1013.

Chwilla, D., \& Kolk, H. J. (2003). Event-related potential and reaction time evidence for inhibition between alternative meanings of ambiguous words. Brain \& Language, 86, 167-192.

Compton, P. E., Grossbacher, P., Posner, M. I., \& Tucker, D. M. (1991). A cognitive-anatomical approach to attention in lexical access. Journal of Cognitive Neuroscience, 3, 304-312.

Connolly, J. F., \& Phillips, N. A. (1994). Event-related potential components reflect phonological and semantic processing of the terminal word of spoken sentences. Journal of Cognitive Neuroscience, 6, 256-266.

Connolly, J. F., Phillips, N. A., Stewart, S. H., \& Brake, W. G. (1992). Event-related potential sensitivity to acoustic and semantic properties of terminal words in sentences. Brain and Language, 43, 1-18.

Connolly, J. F., Stewart, S. H., \& Phillips, N. A. (1990). The effects of processing requirements on neurophysiological responses to spoken sentences. Brain and Language, 39, 302-318.

De Bruijn, E., Dijkstra, T., Chwilla, D., \& Schreifers, H. (2001). Language context effects on interlingual homograph recognition: Evidence from event-related potentials and response times in semantic priming. Bilingualism: Language and Cognition, 4, 155-168.
De Groot, A. M. B. (1984). Primed lexical decision: Combined effects of the proportion of related prime-target pairs and the stimulus-onset asynchrony of prime and target. Quarterly Journal of Experimental Psychology, 36A, 253-280.

De Groot, A. M. B., Delmaar, P., \& Lupker, S. J. (2000). The processing of interlexical homographs in translation recognition and lexical decision: Support for non-selective access to bilingual memory. The Quarterly Journal of Experimental Psychology, 53A, 397-428.

De Groot, A. M. B., \& Nas, G. L. J. (1991). Lexical representation of cognates and noncognates in compound bilinguals. Journal of Memory and Language, 30, 90-123.

De Moor, W. (1998). Visual word recognition in bilinguals. Unpublished master's thesis, University of Ghent.

Dijkstra, T., De Bruijn, E., Schreifers, H., \& Brinke, S. T. (2000). More on interlingual homograph recognition: Language intermixing versus explicitness of instruction. Bilingualism: Language and Cognition, 3, 69-78.

Dijkstra, T., Grainger, J., \& Van Heuven, W. J. B. (1999). Recognition of cognates and interlingual homographs: The neglected role of phonology. Journal of Memory and Language, 41, 496-518.

Dijkstra, T., Timmermans, M., \& Schreifers, H. (2000). On being blinded by your other language: Effects of task demands on interlingual homograph recognition. Journal of Memory and Language, 42, 445-464.

Dijkstra, T., \& Van Heuven, W. J. B. (2002). The architecture of the bilingual word recognition system: From identification to decision. Bilingualism: Language \& Cognition, 5, 175-197.

Dijkstra, T., Van Jaarsveld, H., \& Brinke, S. T. (1998). Interlingual homograph recognition: Effect of task demands and language intermixing. Bilingualism: Language and Cognition, 1, 51-66.

Dufour, R., \& Kroll, J. F. (1995). Matching words to concepts in two languages: A test of the concept mediation model of bilingual representation. Memory and Cognition, 23, $166-180$.

Eimer, M. (1993). Effects of attention and stimulus probability on ERPs in a Go/noGo task. Biological Psychology, 35, $123-138$.

Elston, K. E. (1996). Processing L1 homonyms, polysemous nouns, and cognates in the L2: Evidence of L1 lexical-conceptual relationships as an influential factor in L2 lexical processing. Working Papers in English and Applied Linguistics, 3, 59-78.

Elston-Güttler, K. E. (2000). An enquiry into cross-language lexical-conceptual relationships and their effect on $L 2$ lexical processing. $\mathrm{PhD}$ dissertation, University of Cambridge.

Elston-Güttler, K. E., Gunter, T. C., \& Kotz, S. A. (in press). Zooming in: Global language context and adjustment affect processing of interlingual homographs in sentences. Cognitive Brain Research.

Elston-Güttler, K. E., \& Friederici, A. D. (2005). Native and L2 processing of homonyms in sentential context. Journal of Memory \& Language, 52, 256-283.

Frenck-Mestre, C., \& Prince, P. (1997). Second language autonomy. Journal of Memory and Language, 37, 481-501.

Gascoigne, C. (2001). Lexical and conceptual representations in more- and less-skilled bilinguals: The role of cognates. Foreign Language Annals, 34, 446-452.

Geisser, S., \& Greenhouse, S. W. (1959). On methods in the analysis of profile data. Psychometrika, 24, 95-112.

Gerard, L. D., \& Scarborough, D. L. (1989). Language-specific access of homographs by bilinguals. Journal of 
Experimental Psychology: Learning, Memory, and Cognition, 15, 305-315.

Grainger, J., \& Dijsktra, T. (1992). On the representation and use of language information in bilinguals. In R. J. Harris (Ed.), Cognitive processing in bilinguals (pp. 207-220). Amsterdam: North-Holland.

Green, D. W. (1998). Mental control of the bilingual lexico-semantic system. Bilingualism: Language and Cognition, 1, 67-81.

Gunter, T. C., Wagner, S., \& Friederici, A. D. (2003). Working memory and lexical ambiguity resolution as revealed by ERPs: A difficult case for activation theories. Journal of Cognitive Neuroscience, 15, 1-15.

Jodo, E., \& Kayama, Y. (1992). Relation of a negative ERP component to response inhibition in a Go/noGo task. Electroencephalography and Clinical Neuropsychology, 82, 477-482.

Kawakami, A. (1994). The effect of proficiency in a second language on lexical-conceptual representation. Japanese Journal of Psychology, 64, 426-433.

Keatley, C. W., \& De Gelder, B. (1992). The bilingual primed lexical decision task: Cross-language priming disappears with speeded responses. European Journal of Cognitive Psychology, 4, 273-292.

Keatley, C. W., Spinks, J. A., \& De Gelder, B. (1994). Asymmetrical cross-language priming effects. Memory and Cognition, 22, 70-84.

Kirsner, K., Smith, M. C., Lockhart, R. S., King, M. L., \& Jain, M. (1984). The bilingual lexicon: Language-specific units in an integrated network. Journal of Verbal Learning and Verbal Behavior, 23, 519-539.

Kok, A. (1986). Effects of degradation of visual stimuli on components of the event-related potential (ERP) in Go/noGo reaction tasks. Biological Psychology, 23, 21-38.

Kotz, S. A. (1996). Bilingual memory revisited: An electrophysiological investigation of lexical and semantic representation in fluent bilinguals. Unpublished PhD dissertation, Tufts University.

Kotz, S. A. (2001). Neurolinguistic evidence for bilingual language representation: A comparison of reaction times and event-related brain potentials. Bilingualism: Language and Cognition, 4, 143-154.

Kotz, S. A., \& Elston-Güttler, K. (2004). The role of proficiency on processing categorical and associative information in the $\mathrm{L} 2$ as revealed by reaction times and event-related brain potentials. Journal of Neurolinguistics, 17 , 215-235.

Kramer, A. F., \& Donchin, E. (1987). Brain potentials as indices of orthographic and phonological interaction during word matching. Journal of Experimental Psychology: Learning, Memory, and Cognition, 13, 76-86.

Kroll, J. F., \& De Groot, A. M. B. (1997). Lexical and conceptual memory in the bilingual: Mapping form to meaning in two languages. In A. M. B. De Groot \& J. Kroll (Eds.), Tutorials in bilingualism:

Psycholinguistic perspectives (pp. 169-199). Mahwah, NJ: Erlbaum.

Kroll, J. F., \& Stewart, E. (1994). Category interference in translation and picture naming: Evidence for asymmetric connections between bilingual memory representations. Journal of Memory and Language, 33, $149-174$.

Kroll, J. F., \& Tokowicz, N. (2001). The development of conceptual representations for words in a second language. In J. L. Nicol (Ed.), One mind, two languages: Bilingual language processing (pp. 49-71). Malden, MA: Blackwell.
Levelt, W. J. M. (1989). Speaking: From intention to articulation. Cambridge: MIT Press.

Levelt, W. J. M., Roelofs, A., \& Meyer, A. S. (1999). A theory of lexical access in speech production. Behavioral and Brain Sciences, 22, 1-75.

Möller, K. (1992). Die Form als reine Formsache?: Probleme der Formkongruenz in der deutschen Sprache der Gegenwart. Frankfurt am Main: Peter Lang.

Neely, J. H. (1991). Semantic priming effects in visual word recognition: A selective review of current findings and theories. In D. Besner \& G. W. Humphreys (Eds.), Basic processes in reading-Visual word recognition (pp. 264-337). Hillsdale, NJ: Erlbaum.

Neely, J. H., Keefe, D. E., \& Ross, K. L. (1989). Semantic priming in the lexical decision: Task roles of prospective prime-generated expectancies and retrospective semantic matching. Journal of Experimental Psychology: Learning, Memory, and Cognition, 15, 1003-1019.

Niznikiewicz, M., \& Squires, N. K. (1996). Phonological processing and the role of strategy in silent reading: Behavioral and electrophysiological evidence. Brain E Language, 52, 342-364.

Onifer, W., \& Swinney, D. A. (1981). Accessing lexical ambiguity during sentence comprehension: Effects of frequency of meaning and contextual bias. Memory and Cognition, 9, 225-236.

Rodriguez-Fornells, A., Schmitt, B. M., Kutas, M., \& Münte, T. (2002). Electropsysiological estimates of the time course of semantic and phonological encoding during listening and naming. Neuropsychologia, 40, 778-787.

Scarborough, D. L., Gerard, L., \& Cortese, C. (1984). Independence of lexical access in bilingual word recognition. Journal of Verbal Learning and Verbal Behavior, 23, 84-99.

Seidenberg, M., Tanenhaus, M. K., Leiman, J. M., \& Bienkowski, M. (1982). Automatic access of the meanings of ambiguous words in context: Some limitations of knowledge-based processing. Cognitive Psychology, 14, 489-537.

Smith, M. C., \& Kirsner, K. (1982). Language and orthography as irrelevant features in colour-word and picture-word Stroop interference. Quarterly Journal of Experimental Psychology, 34A, 153-170.

Soares, C., \& Grosjean, F. (1984). Bilinguals in a monolingual and a bilingual speech mode: The effect of lexical access. Memory and Cognition, 12, 380-386.

Swinney, D. A. (1979). Lexical access during sentence comprehension: (Re)consideration of context effects. Journal of Verbal Learning and Verbal Behavior, 18, 545-569.

Thorpe, S., Fize, D., \& Marlot, C. (1996). Speed of processing in the human visual system. Nature, 381, 520-522.

Tokowicz, N. (2001). Meaning representation within and across languages. PhD dissertation, The Pennsylvania State University.

Van den Brink, D., Brown, C. M., \& Hagoort, P. (2001). Electrophysiological evidence for early contextual influences during spoken-word recognition: N200 versus N400. Journal of Cognitive Neuroscience, 13, 967-985.

Van Hell, J. G., \& Dijkstra, T. (2002). Foreign language knowledge can influence native language performance in exclusively native contexts. Psychonomic Bulletin E Review, 9, 780-789.

Van Heste, T. (1999). Visual word recognition in bilinguals: Selective and nonselective activation processes as a function of the experimental task. Unpublished master's thesis, University of Leuven. 
Wagner, S. (1996). Der Einflußlexikalischer Ambiguitäten der Muttersprache bei der Sprachrezeption in der Zweitsprache. Unpublished master's thesis, University of Leipzig.

Weber, H. J. (1996). Homographen-Wörterbuch der deutschen Sprache. Berlin: De Gruyter.

Weber-Fox, C. M., \& Neville, H. J. (1996). Maturational constraints on functional specializations for language processing: ERP and Behavioral evidence in bilingual speakers. Journal of Cognitive Neuroscience, 8 , 231-256.

Williams, J. N. (1994). The relationship between word meanings in the first and second language: Evidence for a common, but restricted, semantic code. European Journal of Cognitive Psychology, 6, 195-220.

Woutersen, M., De Bot, K., \& Welstens, B. (1995). The bilingual lexicon: Modality effects in processing. Journal of Psycholinguistic Research, 24, 289-298. 